\title{
Maternal Obesity and Pre-Pregnancy Folic Acid Supplementation
}

\author{
Nadine Farah Cormac Kennedy Ciara Turner Vicky O'Dwyer \\ Mairead M. Kennelly Michael J. Turner \\ UCD Centre for Human Reproduction, Coombe Women and Infants University Hospital, \\ Dublin, Ireland
}

\section{Key Words}

Maternal obesity · Pre-pregnancy folic acid · Body mass index · Unplanned pregnancy

\begin{abstract}
Objective: The purpose of this nested cohort study was to compare the rate of pre-pregnancy supplementation in obese women with that of women with a normal BMI. Methods: Pregnant women were enrolled at their convenience in a large university hospital. Weight and height were measured in the first trimester and BMI categorised. Results: Of the 288 women, $35.1 \%$ were in the normal, $29.5 \%$ in the overweight and $35.4 \%$ in the obese BMI categories. Only $45.1 \%(n=46)$ of the obese women took pre-pregnancy folic acid compared with $60.4 \%$ $(n=61)$ of women with a normal BMI $(p<0.03)$. The lower incidence of folic acid supplementation in obese women was associated with an unplanned pregnancy in $36.3 \%$ of women compared with $22.8 \%$ in the normal BMI category ( $p$ <.04). Conclusions: Obese women should take folate supplements whether they are planning to conceive or not.
\end{abstract}

Copyright (c) 2013 S. Karger GmbH, Freiburg

\section{Introduction}

Neural tube defects (NTDs) are due to incomplete closure of the neural tube within a month of fertilisation. Anencephaly is incompatible with life: spina bifida and encephalocoele both have a high perinatal and infant mortality. Although $80 \%$ of infants with spina bifida survive, it is associated with varying degrees of physical disability [1].NTDs complicate an estimated one in 1,000 births in the USA, and epidemiological studies have concluded that the risk is increased in obese women [1,2]. In a meta-analysis of 12 studies, unadjusted odds ratio for an NTD-affected pregnancy were 1.22 (95\% CI 0.99-1.49), 1.70 (95\% CI, 1.34-2.15) and 3.11 (95\% 1.75-5.46) among overweight, obese and severely obese women respectively, 
Farah et al.: Maternal Obesity and Pre-Pregnancy Folic Acid Supplementation

compared with normal-weight women [3]. Ten of the 12 studies analysed were conducted in the USA. The reason for this association between maternal obesity and the increased risk of NTDs remains unknown [3].

Peri-conceptual folate supplementation has a strong protective effect against NTDs and is recommended for all women considering pregnancy [4]. Using data from the National Health and Nutrition Examination Surveys (NHANES 1988-1994 and 1999-2000), increased BMI in childbearing-age women was associated with a lower serum folate in both surveys $(\mathrm{p}<0.001)$ [5]. Thus, in the UK high-dose $(5 \mathrm{mg})$ folic acid has recently been recommended for obese women planning to conceive [6]. The prevalence of maternal obesity, based on a BMI $>29.9 \mathrm{~kg} / \mathrm{m}^{2}$, is increasing in frequency world-wide which may potentially lead to an increase in congenital malformations $[6,7]$.

The purpose of this nested cohort study was to compare the rate of pre-pregnancy folic acid supplementation in women at risk of developing gestational diabetes mellitus (GDM).

\section{Material and Methods}

This nested cohort study was conducted in a large university teaching hospital between July 2008 and June 2010. The study was confined to white European women with a singleton pregnancy. After a dating scan in the first trimester, weight and height were measured accurately and BMI was calculated. At the first antenatal visit, clinical and socio-demographic details were computerised for subsequent analysis by BMI category according to the WHO BMI classification. As part of the standard hospital antenatal questionnaire, women were asked whether they took pre-conceptual folic acid, whether they planned their pregnancy and whether they were using hormonal contraception when they conceived. The Hospital policy is to screen selectively for GDM based on risk factors. Women were enrolled at their convenience after a diagnostic 100 g oral glucose tolerance test (GTT) at 28 weeks gestation ruled out GDM as part of a larger study on foetal body composition in the third trimester.

The study was passed by the Hospital's Research Ethics Committee in June 2008. Data was analysed using SPSS Version 18.0 (SPSS Inc, Chicago, IL, USA). The chi-square test was used to analyse differences between the groups. A p value $<0.05$ was considered as statistically significant.

\section{Results}

The subject characteristics analysed by BMI category are shown in table 1 . Of the 288 women studied, 101 (35.1\%) were in the normal BMI category, 85 (29.5\%) were in the overweight category and $102(35.4 \%)$ were in the obese category. The proportion of obese women enrolled was high because a maternal weight $\geq 90 \mathrm{~kg}$ in early pregnancy was one of the indications for selective screening for GDM. Table 2 shows folic acid supplementation analysed by BMI category. Only $45.1 \%(n=46)$ of the obese women took pre-pregnancy folic acid compared with $60.4 \%(\mathrm{n}=61)$ in the women with a normal BMI $(\mathrm{p}<0.03)$. The dose of folic acid was recorded in only $36 \%$ of the 158 women who took it before pregnancy. None of the 46 obese women reported taking the higher dose of $5 \mathrm{mg}$ before pregnancy.

The lower incidence of folic acid supplementation in obese women was due, in part, to the fact that the pregnancy was unplanned in $36.3 \%(n=37)$ of cases compared with $22.8 \%$ $(\mathrm{n}=23)$ in women with normal BMI $(\mathrm{p}<0.04)$. Obese women reported a hormonal contraceptive failure rate of $14.7 \%(n=15)$ compared with $5.9 \%(n=6)$ in women with normal BMI $(p=0.04)$. Of the obese women who planned their pregnancy $(n=65), 63.1 \%(n=41)$ took pre-pregnancy supplementation compared with $76.9 \%(n=60)$ in women with normal BMI $(n=78)$ who planned their pregnancy $(p=0.07)$. None of the babies in the study had a major congenital malformation. 
Farah et al.: Maternal Obesity and Pre-Pregnancy Folic Acid Supplementation

Table 1. Subject characteristics analysed by BMI category $(\mathrm{n}=288)$
Table 2. Pre-pregnancy details analysed by BMI category

\begin{tabular}{llll}
\hline & $\begin{array}{l}\text { Normal } \\
(\mathrm{n}=101)\end{array}$ & $\begin{array}{l}\text { Overweight } \\
(\mathrm{n}=85)\end{array}$ & $\begin{array}{l}\text { Obese } \\
(\mathrm{n}=102)\end{array}$ \\
\hline BMI category, kg/m² & $18.5-24.9$ & $25.0-29.9$ & $>29.9$ \\
Mean weight, kg & 61.9 & 73.8 & 94.3 \\
Mean BMI, kg/m² & 22.6 & 27.3 & 35.2 \\
Mean height, cm & 165 & 163 & 164 \\
Mean age, years & 30.8 & 31.2 & 30.6 \\
Primiparous, \% & 38.6 & 35.3 & 37.3 \\
Smokers, \% & 16.8 & 20.0 & 14.7 \\
Caesarean section, \% & 22.8 & 23.4 & 26.5 \\
Gestation at delivery, weeks & 40.0 & 39.9 & 39.5 \\
Previous miscarriages, \% & 29.7 & 34.1 & 34.3 \\
Mean birth weight, g & 3,582 & 3,696 & 3,524 \\
\hline
\end{tabular}

\begin{tabular}{llll}
\hline $\begin{array}{l}\text { BMI category, } \\
\mathrm{kg} / \mathrm{m}^{2}\end{array}$ & $\begin{array}{l}\text { Took folic acid } \\
\text { supplements }\end{array}$ & $\begin{array}{l}\text { Unplanned } \\
\text { pregnancy }\end{array}$ & $\begin{array}{l}\text { Failed hormonal } \\
\text { contraception }\end{array}$ \\
\hline $18.5-24.9(\mathrm{n}=101)$ & $61(60.4 \%)$ & $23(22.8 \%)$ & $6(5.9 \%)$ \\
$25.0-29.9(\mathrm{n}=85)$ & $51(60.0 \%)$ & $23(27.1 \%)$ & $8(9.4 \%)$ \\
$>29.9(\mathrm{n}=102)$ & $46(45.1 \%)$ & $37(36.3 \%)$ & $15(14.7 \%)$ \\
Normal vs. obese & $\mathrm{p}=0.029$ & $\mathrm{p}=0.035$ & $\mathrm{p}=0.04$ \\
\hline
\end{tabular}

\section{Discussion}

We found that obese women were less likely to take pre-pregnancy folic acid supplementation than women with a normal BMI. This appears to be due to a higher number of unplanned pregnancies in obese women, partly as a result of unsuccessful hormonal contraception. The lower rate of folic acid supplementation may explain the increased risk of NTDs in obese women reported in a recent meta-analysis [3].A weakness in our study is that we do not have reliable information on the socio-economic status of the women. Social deprivation may lead to both an increase in obesity levels and an increase in unplanned pregnancies and, thus, result in inadequate pre-pregnancy folic acid supplementation. Another weakness of our study was that in our hospital questionnaire we do not address the period of time that the folic acid was taken for and the compliance.

Although the numbers in our study are small, it has a number of strengths. Firstly, the study design avoided some confounding variables. Maternal obesity and GDM may increase the risk of NTDs through shared causal mechanisms [8]. However, all participants in our study had GDM ruled out by a diagnostic GTT. The risk of NTDs may vary with ethnicity or multiple pregnancies but our study was confined to white European women with a singleton pregnancy [9].

Secondly, BMI was based on accurate measurements of weight and height, and not selfreporting, in the first trimester. Previous studies usually based BMI categorisation on selfreporting of weight, which is known to be inaccurate in both obese and female subjects $[3,10$, 11]. Previous reports may also be based on pre-pregnancy BMI or weight which is often not available in unplanned pregnancies. We have recently reported that, contrary to expectations, mean BMI or adiposity does not change in the first trimester [12]. Thus, BMI categories should ideally be classified in early pregnancy rather than pre-pregnancy. 
Farah et al.: Maternal Obesity and Pre-Pregnancy Folic Acid Supplementation

A large retrospective Canadian population study between 1994 and 2000, based on selfreported weight of women who underwent screening at 15-20 weeks gestation, found a higher risk of NTDs associated with increased maternal weight, even after the introduction of universal folic acid fortification in late 1997 [2]. Information, however, was not reported on folic acid supplementation rates in women with higher weights.

The introduction of mandatory food fortification with folic acid has been associated with a decline in the prevalence of open NTDs in the USA and Canada [14]. However, the decline has not been as great as predicted from earlier randomised controlled trials [14]. Increased obesity levels in North American women of childbearing age may be associated with lower supplementation rates and poor dietary intake of folate.

In the USA, Hispanic women have a higher risk of NTDs than other ethnic groups [9]. In the 2003-2004 NHANES, obesity levels were 42.3\% in Hispanic women compared with $30.2 \%$ in non-Hispanic white women [13]. In the recent analysis of 2,617 non-pregnant women aged 15-44 years from the 2003-2006 NHANES, the estimated prevalence of women taking folic acid supplements was $31.7 \%$ [4]. Supplements were taken by only $20 \%$ (95\% CI 15.3-25.7\%) of Hispanic women compared with 37.2\% (95\% CI 31.7-43.0\%) of non-Hispanic white women [4]. Information was not presented on whether the women were planning to conceive or not in the near future. The increased risk of NTDs in Hispanic women may be explained if increased numbers of obese women do not take pre-pregnancy folic acid supplementation because they are not planning to conceive. Lower pre-pregnancy supplementation in obese women may also contribute to the lower serum folate levels found in women with a high BMI in the earlier National Surveys [5].

In the USA, $49 \%$ of all clinical pregnancies are unplanned, and about half of these occur in couples using contraception [15]. In Oregon, folic acid supplements were taken by $45.3 \%$ of women $(n=948)$ planning to conceive compared with only $14.8 \%(n=681)$ of women not intending to conceive [16]. Obese women are less likely to use contraception, but the reason for this is unclear [17]. There is also uncertainty as to whether hormonal contraception is less effective or compliance is poorer in obese women than in non-obese [18, 19].

In a case-control study of 248 women in Washington, the risk of pregnancy among all oral contraception users was $70 \%$ higher in women with a BMI $>32.2 \mathrm{~kg} / \mathrm{m}^{2}$ (OR $1.72,95 \% \mathrm{CI}$ 1.04-2.82) compared with women having a BMI $<27.4 \mathrm{~kg} / \mathrm{m}^{2}[20]$. In this study weight was measured and was $2 \mathrm{~kg}$ on average above the self-reported weight. In a population-based study, no association was found between obesity and oral contraceptive failure, but BMI calculations were based on self-reporting [21].

There is a dearth of information about the efficiency and safety of hormonal contraception in obese women, particularly in women with a BMI $>34.9 \mathrm{~kg} / \mathrm{m}^{2}$ or with obesity co-morbidities, because pharmaceutical trials have often excluded obese women [17, 22]. There is, however, evidence that obese women show differences in oral contraceptive pharmacokinetics that are associated with greater hypothalamic-pituitary-ovarian activity compared to women with a normal BMI [23].

Ideally from evidence in the literature, all obese women should start high-dose folic acid supplementation and lose weight before they conceive $[2,6]$. Our findings also suggest that obese women in the childbearing age groups, in particular, should be supplementing their folic acid intake, whether they are trying to conceive or not.

\section{Disclosure Statement}

The authors have no potential conflicts of interest to disclose. 
Farah et al.: Maternal Obesity and Pre-Pregnancy Folic Acid Supplementation

\section{References}

1 Watkins ML, Scanlon KS, Mulinare J, Khoury MJ: Is maternal obesity a risk factor for anencephaly and spina bifida? Epidemiology 1996;7:507-511.

-2 Ray JG, Wyatt PR, Vermeulan MJ, Meier C, Cole DE: Greater maternal weight and the ongoing risk of neural tube defects after folic acid flour fortification. Obstet Gynecol 2005;105:261-265.

-3 Rasmussen SA, Chu SY, Kim SY, Schmid CH, Lau J: Maternal obesity and risk of neural tube defects: a metaanalysis. Am J Obstet Gynecol 2008;198:611-619.

-4 Tinker SC, Cogswell ME, Devine 0, Berry RJ: Folic acid intake among US women aged 15-44 years, National Health and Nutrition Examination Survey, 2003-2006. Am J Prev Med 2010;35:534-542.

5 Mojtabai R: Body mass index and serum folate in childbearing age women. Eur J Epidemiol 2004;19:10291036.

6 Centre for Maternal and Child Enquires and Royal College of Obstetricians and Gynaecologists Joint Guideline: Management of women with obesity in pregnancy. Centre for Maternal and Child Enquiries, London, 2010.

7 Barry S, Fattah C, Farah N, Broderick V, Stuart B, Turner MJ: The growing challenge of maternal obesity (editorial). Ir Med J 2009;102:5-6.

8 Anderson JL, Waller DK, Canfield MA, Shaw GM, Watkins ML, Werler MM: Maternal obesity, gestational diabetes, and central nervous system birth defects. Epidemiology 2005;16:87-92.

19 Frey L, Hauser WA: Epidemiology of neural tube defects. Epilepsia 2003;44:4-13.

10 Niedhammer I, Bugel I, Bonenfant S, Goldberg M, Leclerc A: Validity of self-reported weight and height in the French GAZAL cohort. Int J Obes Relat Metab Disord 2000;24:1111-1118.

11 Fattah C, Farah N, O’Toole F, Barry S, Stuart B, Turner MJ: Body mass index (BMI) in women booking for antenatal care: comparison between selfreported and digital measurements. Eur J Obstet Gynecol Reprod Biol 2009;144:32-34.

12 Fattah C, Farah N, Barry S, O'Connor N, Stuart B, Turner MJ: Maternal weight and body composition in the first trimester of pregnancy. Acta Obstet Gynecol Scand 2010;89:952-955.

-13 Ogden C, Carroll M, CurtinL, McDowell M, Tabak C, Flegal K: Prevalence of overweight and obesity in the United States, 1999-2004. JAMA 2006;295:1549-1555.

14 Boulet SL, Yang Q, Mai C, Kirby SL, Collins JS, Robbins JM, Meyer R, Canfield MA, Mulinare J: Trends in the postfortification prevalence of spina bifida and anencephaly in the United States. Birth Defects Res A Clin Mol Teratol 2008;82:527-532.

15 Finer LB, Henshaw SK: Disparities in rates of unintended pregnancy in the United States, 1994 and 2001. Perspect Sex Reprod Health 2006;38:90-96.

16 Rosenberg KD, Gelow JM, Sandoval AP: Pregnancy intendedness and the use of periconceptional folic acid. Pediatrics 2003;111:1142-1145.

17 Society of Family Planning Research Education and Leadership: Contraceptive considerations in obese women. Contraception 2009;80:583-590.

18 Trussell J, Schwarz EB, Guthrie K: Obesity and oral contraceptive pill failure. Contraception 2009;79:334-338.

19 Lopez LM, Grimes DA, Chen-Mok M, Westhoff C, Edelman A, Helmerhorst FM: Hormonal contraceptives for contraception in overweight or obese women. Cochrane Database Syst Rev 2010; 7:CD008452.

20 Holt VL, Scholes D, Wicklund KG, Cushing-Haugen KL, Daling JR: Body Mass index, weight and oral contraceptive failure risk. Obstet Gynecol 2005;105:46-52.

21 Brunner Huber LR, Toth JL: Obesity and oral contraceptive failure: findings from the 2002 national survey of family growth. Am J Epidemiol 2007;166:1306-1311.

-22 Burkman RT, Fisher AC, Wan GJ, Barnowski CE, LaGuardia KD: Association between efficacy and body weight or body mass index for two low-dose oral contraceptives. Contraception 2009;79:424-427.

-23 Edelman AB, Carlson NE, Cherala G, Munar MY, Stouffer RL, Cameron JL, Stanczyk FZ, Jensen JT: Impact of obesity on oral contraceptive pharmacokinetics and hypothalamic-pituitary-ovarian activity. Contraception 2009;80:119-127. 